Original Research Paper

\title{
Glucan Supplementation Regulates Secretory Immunity and Stress
}

\author{
${ }^{1}$ Richter Josef, ${ }^{1}$ Stiborová Ivana, ${ }^{1}$ Král Vlastimil, \\ ${ }^{2}$ Svozil Vladimir, ${ }^{3}$ Vetvicka Vaclav and ${ }^{1}$ Rajnohová Dobiášová Lucie \\ ${ }^{I}$ Zdravotni Ústav se Sidlem v Ústi nad|Labem, Czech Republic \\ ${ }^{2}$ Sanatorium EDEL Zlaté Hory, Czech Republic \\ ${ }^{3}$ Department of Pathology, University Louisville, Louisville, USA
}

\author{
Article history \\ Received: 15-11-2016 \\ Revised: 16-01-2017 \\ Accepted: 29-03-2017 \\ Corresponding Author: \\ Vetvicka Vaclav \\ Department of Pathology, \\ University of Louisville, \\ Louisville, KY 40202, USA. \\ Fax: 502-852-7674 \\ Email:Vaclav.vetvicka@louisville.edu
}

\begin{abstract}
Sixty-six children were supplemented with beta glucan and dietary nucleotides, another 63 children served as negative control. We evaluated the effects of these supplements on several aspects of secretory immunity such as levels of secretory $\operatorname{IgA}(\mathrm{SIgA})$, albumin and $\mathrm{SIgA} /$ albumin ratio. In addition, in order to monitor effects of physical challenges and compensatory treatments on stress and reparation of immunity, we measured levels of salivary cortisol. We found significant effects of supplementation with beta glucan on secretory IgA in children with increased physical challenge. To fully explain these findings, we will need to add additional indicators of stress and salivary immunity.
\end{abstract}

Keywords: Saliva, Salivary IgA, Cortisol, Beta Glucan, Dietary Nucleotides

\section{Introduction}

Salivary IgA represents an important component participating in anti-infectious defense of an organism. Its levels fluctuate depending on numerous factors including circadian rhythms with extreme increases during early morning hours (6-8 AM) followed by subsequent decrease during late morning, afternoon stabilization and gradual increase later in the day (Richter et al., 1980). Several studies repeatedly demonstrated relations between SIgA variations and psychological stress of students (Guo et al., 2002). Levels of SIgA are influenced by additional factors such as amount of water consumption (Backes et al., 2015), physical activity and physical challenge (Cieslak et al., 2003; Dwyer et al., 2010; Gleeson and Pyne, 2000), changes in biorhythms during work shift (Guo et al., 2002; Lac and Chamoux, 2003), time of the season, location, altitude above sea level and most of all by stress related to psychological challenge and persisting physical challenge (Cieslak et al., 2003; Cohen et al., 2001; Gleeson and Pyne, 2000; Guo et al., 2002; Hunter et al., 2011; Kidd et al., 2011; Powell et al., 2015; Yang et al., 2002). Two major branches of stress induction include autonomous nervous system and hypothalamus-adrenal gland-pituitary axis. These two systems coordinate sensitivity of additional physiological systems affecting immunity (Marques et al, 2010).

The salivary albumin level reflects capillary penetration of this protein into saliva and is a dependable indicator of inflammatory response to infectious and noninfectious impulses (Richter et al., 1980; 2015c). Low levels of serum albumin reflect inflammatory reaction of organism and represent negative protein of inflammatory reaction. The situation in saliva is different, as increase albumin levels might suggest actual as well as latent inflammatory reaction. Elevated level finding in saliva usually leads to verification of possible infection including bacterial and viral infections, sinusitis and dental problems including gingivitis. However, there is a possibility of saliva contamination caused by vigorous dental treatment. Changes in capillary penetration during inflammation may influence the levels of salivary IgA and evaluation of the $\operatorname{IgA} /$ albumin ratio is important (Cieslak et al., 2003; Dwyer et al., 2010).

Current literature offers clear evidence showing that psychological stress affects human immune reactions (Cieslak et al., 2003; Mizawa et al., 2013). Some studies have demonstrated that stress can significantly influence antibody response of vaccinated individuals (Cohen et al., 2001). This decrease of antibody 
formation can result from both actual and/or chronic stress. Psychological stress is defined as a result of direct negative experience or even expectation of problems. Some studies suggested that the relationship between stress and antibody response is regulated mostly by glucocorticoids such as cortisol, catecholamin, epinefrin and norepinefrin (Cohen et al., 2001; Marques et al., 2010). Additional factors known to influence stress reaction, particularly in children, are effects of passive smoking, obesity, nutrition, social-economic conditions and environmental pollution (Backes et al., 2015; Cohen et al., 2001). Depression of ability of antibody response in vaccinated population might be connected with significant changes of salivary IgA (Cohen et al., 2001). Quality of nutrition significantly influences gut microbiome with subsequent effects on nonspecific and specific immune reactions. Microbiome of gastrointestinal tract directly influences afferent neurones of gastrointestinal tract and transfers impulses via nervus vagus. Microbiome thus plays a role in stress regulation of hypopituitary adrenal axis (Cohen et al., 2001). Stress reaction accompanied by an increase of salivary cortisol levels might result in reactivation of some infectious diseases such as Epstein-Barr viral infection (Breivik et al., 1996; Stowe et al., 2001).

Nutritional changes can also influence immune reactions; this includes the use of dietary polysaccharides and other supplements. A solid review summarizes immunomodulatory activities of various botanical extracts in both animal and human models (Ramberg et al., 2010). Beta glucans are known for not only reduction of clinical manifestation of respiratory infections, but also for regulation of the psychological state of patients (Talbott and Talbott, 2012). A large study using dogs showed regulation of general as well as antigen specific IgA and IgM reactions (Stuyven et al., 2010). Lehne et al. (2006) confirmed findings of positive effects of glucan supplementation on improvements of immune reactions (Richter et al., 2015a; 2015b; 2015c). It is clear that insoluble dietary fiber playsan important role in the regulation of both immune reactions and psychological state. With beta glucan being an established immunomodulator, more and more studies are focused on food supplementation with beta glucans. However, more studies are necessary to reach clear conclusions (Talbott and Talbott, 2012).

\section{Materials and Methods}

Our study used 126 children aged 6 to 12 years. Group 1 represented children supplemented with glucan (BG) and consisted of 6 males and 19 females. Dietary nucleotide (Imuregen-Uniregen Hradec Kralove Czech Republic)-supplemented group involved 41 children (16 males and 25 females). A control group was formed of
63 children (29 males and 34 females). The age differences between individual groups were not statistically significant. All parents were fully informed about the aim of this study and provided signed consent. Children were evaluated during their medical stay at Sanatorium EDEL Zlate Hory. During the 28 to 32-day stay, the children were regularly examined with particular attention to respiratory problems and daily control by a physician and with evaluation of quality of pulmonary functions including spirometry and evaluation of expiratory exhaled nitric oxide.

The medical regime offered several advantages including improved living conditions, optimal nutrition, regular daily physical strain and several hours of stay in cave (fully confirming conditions for speleotherapy). Physical conditions were evaluated before and after the end of the stay using a $6 \mathrm{MWT}$ test. All results and final recommendations for subsequent treatment were offered at the end of medical stay. Our study was fully in agreement with a Helsinki declaration (revised version 2000.0901) and was in full compliance with the rules for clinical testing in the Czech Republic.

Saliva was obtained at the same time interval, between 8 and 9 AM. Sample tampons Salivette (Sarstead, Orsay, France) gently chewed in mouth for 2 min were used for all experiments. After subsequent centrifugation at $1000 \mathrm{~g}$ for $15 \mathrm{~min}$, the samples were stored at $-18^{\circ} \mathrm{C}$. IgA and albumin levels were evaluated using a Siemens BM II nephelometer with kits and controls obtained directly from manufacturer. Salivary cortisol was measured using high sensitivity salivary cortisol from Salimetrix (Salimetric LLC, UK) as recommended by manufacturer.

\section{Statistical Analysis}

Statistical significance was evaluated by a pair $t$ test using GraphPad Prism 5.04 software (GraphPad Software, USA). An average and standard deviation was evaluated after determination of composition of standard values (D'Agostino, Pearson). In case of nonstandard composition, we converted the values into logarithms.

\section{Results}

Table 1 summarizes data obtained in this study. The glucan supplemented group had statistically significant decrease of SIgA levels from 302.7 to $182.4 \mathrm{mg} \mathrm{L}^{-1}$. Similarly, the levels of salivary albumin were found to be lower at the end of the study (Fig. 1) However, this decrease was not significant. An increase of cortisol levels from 3.18 to $4.34 \mathrm{ug} \mathrm{L}^{-1}$ was statistically significant. The other studied groups showed no significant changes in cortisol levels or SIgA levels (Fig. 2). 


\begin{tabular}{|c|c|c|c|c|c|c|c|c|c|}
\hline \multirow[b]{2}{*}{ Group } & & \multicolumn{2}{|c|}{$\mathrm{S}$ IgA mg/L } & \multicolumn{2}{|c|}{ Albumin $\mathrm{mg} / \mathrm{L}^{-1}$} & \multicolumn{2}{|c|}{ SIgA/Albumin } & \multicolumn{2}{|c|}{ Cortisol $\mu \mathrm{g} / \mathrm{L}^{-1}$} \\
\hline & & $\mathrm{A}$ & $\mathrm{B}$ & A & $\mathrm{B}$ & $\mathrm{A}$ & $\mathrm{B}$ & A & $\mathrm{B}$ \\
\hline \multirow[t]{4}{*}{1} & $\mathrm{n}$ & 25.0000 & 25.00 & 25.0000 & 25.00 & 25.0000 & 25.00 & 25.0000 & 25.000 \\
\hline & mean & 302.7000 & 182.40 & 145.5000 & 103.50 & 2.8300 & 2.21 & 3.1760 & 4.336 \\
\hline & SD & 28.8000 & 28.90 & 16.9000 & 30.20 & 1.3700 & 1.28 & 1.8240 & 2.516 \\
\hline & $\mathrm{P}$ & 0.0151 & & 0.1040 & & 0.1550 & & 0.0085 & \\
\hline \multirow[t]{4}{*}{2} & $\mathrm{n}$ & 41.0000 & 41.00 & 41.0000 & 41.00 & 41.0000 & 41.00 & 41.0000 & 41.000 \\
\hline & mean & 93.1100 & 68.84 & 151.5000 & 61.70 & 2.2700 & 2.47 & 2.9880 & 2.154 \\
\hline & SD & 30.2000 & 35.70 & 47.7000 & 75.00 & 2.0200 & 2.38 & 2.5600 & 1.890 \\
\hline & $\mathrm{P}$ & 0.1310 & & 0.0295 & & 0.6911 & & 0.0612 & \\
\hline \multirow[t]{4}{*}{3} & $\mathrm{n}$ & 63.0000 & 63.00 & 63.0000 & 63.00 & 63.0000 & 63.00 & 63.0000 & 63.000 \\
\hline & mean & 88.9000 & 76.30 & 87.4200 & 85.04 & 2.6500 & 2.79 & 2.3540 & 2.085 \\
\hline & SD & 31.2000 & 35.80 & 11.0100 & 10.89 & 2.5300 & 2.51 & 1.8900 & 1.950 \\
\hline & $\mathrm{P}$ & 0.1868 & & 0.4240 & & 0.6892 & & 0.1620 & \\
\hline
\end{tabular}

\section{IgA saliva}

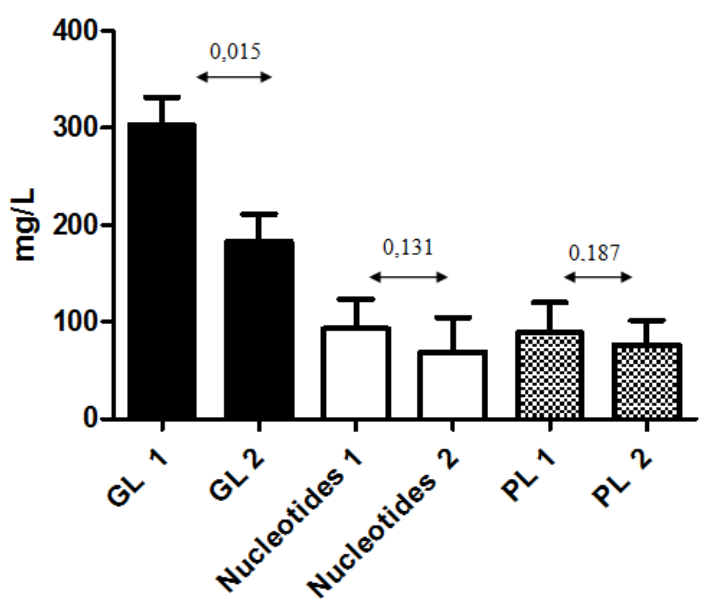

Fig. 1. Effect of supplementation with Glucan (GL), dietary nucleotides (Nucleotides) and Placebo (PL) on salivary IgA

\section{Albumin saliva}

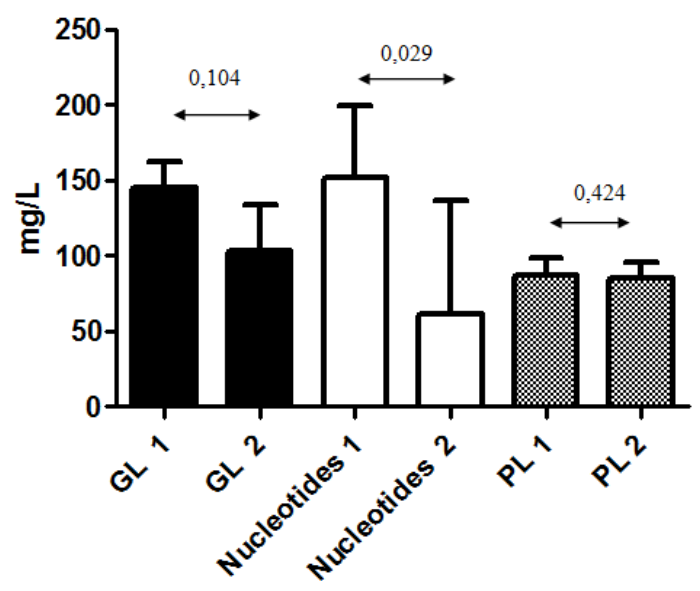

Fig. 2. Effect of supplementation with glucan (GL), dietary nucleotides (Nucleotides) and placebo (PL) on levels of albumin in saliva

\section{Cortisol saliva}

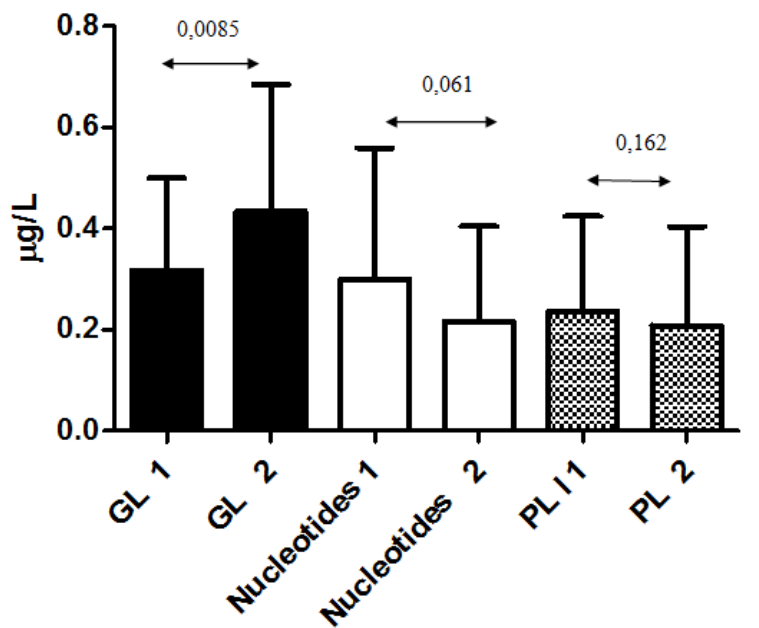

Fig. 3. Effect of supplementation with glucan (GL), dietary nucleotides (Nucleotides) and placebo (PL) on level of cortisol in saliva

The nucleotide-supplemented group showed significant decrease of albumin levels (Fig. 3). A similar, albeit insignificant, trend was found in the glucan-supplemented group, which might be a result of the limited number of children. SIgA/albumin ratio showed no significant differences between beginning and end values.

\section{Discussion}

Two supplemented groups were evaluated during their medical stay at Sanatorium EDEL in Zlate Hory. Both groups had differed significantly in examination at the starting point, in basic diagnosis (chronic respiratory problems) and at the time of examination. Glucan-supplemented children were evaluated in March and April, whereas other groups were evaluated at the beginning of fall. In the glucan group we could 
clearly observe a clinical picture based on the winter period and location with high level of pollution-high SIgA levels together with indications of inflammation; i.e., high level of albumin mediated by extreme capillary penetration into saliva. SIgA levels in children supplemented with nucleotides and in the control group were lower due to the summer season and location without significant pollution (family summer vacation at sea, etc.). Among the children tested in spring, we found a strong decrease in levels of tested molecules, but it still did not reach normal range described for this age category. We can again confirm that reparation of immune reactions with subsequent significant reduction of bacterial and viral infections needs a long term stay in medical regime. These findings are even more pronounced in children exposed to secondhand smoke. We found that more than $50 \%$ of Czech children are exposed to secondhand smoke. We expected to see significant decrease of cortisol levels in the glucansupplemented group, but conversely we found an increase of this molecule. We hypothesize that this increase was caused by the higher physical load during their stay at the sanatorium-forced physical education, long daily walks and rehabilitative exercise. It is also known that intensive physical exercise can result in lower SIgA levels (Gleeson and Pyne, 2000). It is possible that higher cortisol levels might be, at least partly, influenced by acute stress from sample collection, when expectation of arrival of family members and return home might change the stress level. In children tested after summer holiday we also found higher levels of cortisol, but during the supplementation we found decrease. The control group of children and their optimal levels of all tested parameters were probably caused by after holiday reparation of immune functions and minimal physical burden at the sample collection (usually only $2 \times 45 \mathrm{~min}$ of mandatory school exercise at school). In the nucleotide-supplemented group we found nonsignificant decrease of SIgA level, but also significant decrease of inflammatory reaction presented by albumin levels. Dietary nucleotides can significantly help to repair intestinal mucosa and probably positively influence microbiome and subsequently repair inflammatory response.

\section{Conclusion}

For additional evaluation and explanation of the relationship between stress and immune response, it is necessary to further evaluate additional factors, particularly seasonal changes, nutritional background and weight of children. As in other developed countries, the number of obese children in the Czech Republic is steadily.

\section{Acknowledgment}

This study was supported by the Technology Agency of the Czech Republic TACR TA 0202094.

\section{Author's Contributions}

All authors contributed equally.

\section{Ethics}

Our study was fully in agreement with a Helsinki declaration (revised version 2000.0901) and was in full compliance with the rules for clinical testing in the Czech Republic.

\section{References}

Backes, T.P., P.J. Horvath and K.A. Kazial, 2015. Salivary alpha amylase and salivary cortisol response to fluid consumption in exercising athletes. Biol. Sport, 32: 275-280.

DOI: $10.5604 / 20831862.1163689$

Breivik, T., P.S. Thrane, R. Murison and P. Gjermo, 1996. Emotional stress effects on immunity, gingivitis and periodontitis. Eur. J. Oral. Sci., 104: 327-334.

Cieslak, T.J., G. Frost and P. Klentrou, 2003. Effects of physical activity, body fat and salivary cortisol on mucosal immunity in children. J. Applied Physiol., 95: 2315-2320.

DOI: 10.1152/japplphysiol.00400.2003

Cohen, S., G.E. Miller and B.S. Rabin, 2001. Psychological stress and antibody response to immunization: A critical review of the human literature. Psychosom Med., 63: 7-18.

Dwyer, D.B., C.K. Booth, P.F. Pacque and M.J. Ball, 2010. Considerations for the use of salivary $\operatorname{IgA}$ for monitoring mucosal immune function. Aviat. Space Environ. Med., 81: 581-584.

Gleeson, M. and D.B. Pyne, 2000. Special feature for the Olympics: Effects of exercise on the immune system: Exercise effects on mucosal immunity. Immunol. Cell Biol., 78: 536-544. DOI: 10.1111/j.1440-1711.2000.t01-8-.x

Guo, Z.Q., T. Otsuki, Y. Ishi, A. Inagaki and Y. Kawakami et al., 2002. Perturbation of secretory IgA in saliva and its daily variation by academic stress. Environ. Health Prev. Med., 6: 268-272. DOI: 10.1007/BF02897981

Hunter, A.L., H. Minnis and P. Wilson, 2011. Altered stress responses in children exposed to early adversity: A systematic review of salivary cortisol studies. Stress, 14: 614-626.

DOI: $10.3109 / 10253890.2011 .577848$ 
Kidd, T., M. Hamer and A. Steptoe, 2011. Examining the association between adult attachment style and cortisol responses to acute stress. Psychoneuroendocrinology, 36: 771-779.

DOI: 10.1016/j.psyneuen.2010.10.014

Lac, G. and A. Chamoux, 2003. Elevated salivary cortisol levels as a result of sleep deprivation in a shift worker. Occup. Med., 53: 143-145.

Lehne, G., B. Haneberg, P. Gaustad, P.W. Johansen and H. Preus et al., 2006. Oral administration of a new soluble branched beta-1,3-D-glucan is well tolerated and can lead to increased salivary concentrations of immunoglobulin A in healthy volunteers. Clin. Exp. Immunol., 143: 65-69.

DOI: $10.1111 /$ j.1365-2249.2005.02962.x

Marques, A.H., M.N. Silverman and E.M. Sternberg, 2010. Evaluation of stress systems by applying noninvasive methodologies: Measurements of neuroimmune biomarkers in the sweat, heart rate variability and salivary cortisol. Neuroimmunomodulation, 17: 205-208. DOI: $10.1159 / 000258725$

Mizawa, M., M. Yamaguchi, C. Ueda, T. Makino and T. Shimizu, 2013. Stress evaluation in adult patients with atopic dermatitis using salivary cortisol. BioMed. Res. Int., 2013: 138027-138027. DOI: $10.1155 / 2013 / 138027$

Powell, J., T. DiLeo, R. Roberge, A. Coca and J.H. Kim, 2015. Salivary and serum cortisol levels during recovery from intense exercise and prolonged, moderate exercise. Biol. Sport, 32: 91-95. DOI: $10.5604 / 20831862.1134314$

Ramberg, J.E., E.D. Nelson and R.A. Sinnott, 2010. Immunomodulatory dietary polysaccharides: A systematic review of the literature. Nutr. J., 9: 54-54. DOI: $10.1186 / 1475-2891-9-54$

Richter, J., V. Kral, I. Zukov, P. Subrt and J. Rahm, 1980. Circadian changes of the SIgA, lysozyme, albumin and copper content of saliva. Czech Med., 3: $249-54$.
Richter, J., V. Kral, I. Stiborova, D. Rajnohová and V. Vetvicka, 2015a. Anti-inflammatory effects of $\beta$ glucan in cancer related fatigue. J. Nutrit. Health Sci., 3: 304-304. DOI: 10.15744/2393-9060.2.304

Richter, J., V. Svozil, V. Kral, L. Rajnohova Dobiasova and I. Stiborova et al., 2015b. Effects of dietary nucleotides on immune mechanisms and physical state in children with chronic respiratory problems. Am. J. Immunol., 11: 26-32. DOI: 10.3844 ajisp.2015.26.32

Richter, J., V. Svozil, V. Kral, L. Rajnohova Dobiasova and V. Vetvicka, 2015c. Beta-glucan affects mucosal immunity in children with chronic respiratory problems under physical stress. Clin. Trials. Ann. Transl. Med., 3: 52-52. DOI: $10.3978 /$ j.issn.2305-5839.2015.03.20

Stowe, R.P., D.L. Pierson and A.D. Barrett, 2001. Elevated stress hormone levels relate to EpsteinBarr virus reactivation in astronauts. Psychosom Med., 63: 891-895.

Stuyven, E., F. Verdonck, I. Van Hoek, S. Daminet and L. Duchateau et al., 2010. Oral administration of beta-1,3/1,6-glucan to dogs temporally changes total and antigen-specific $\operatorname{IgA}$ and $\operatorname{IgM}$. Clin. Vaccine Immunol., 17: 281-285. DOI: $10.1128 / \mathrm{CVI} .00344-09$

Talbott, S.M. and J.A. Talbott, 2012. Baker's yeast betaglucan supplement reduces upper respiratory symptoms and improves mood state in stressed women. J. Am. Coll. Nutr., 31: 295-300.

Yang, Y., D. Koh, V. Ng, C.Y. Lee and G. Chan et al., 2002. Self perceived work related stress and the relation with salivary $\operatorname{IgA}$ and lysozyme among emergency department nurses. Occup. Environ. Med., 59: 836-841. 